Egyptian

Orthodontic Journal

\title{
FRICTIONAL CHARACTERISTICS OF ACTIVE SELF-LIGATING BRACKETS VERSUS CONVENTIONAL BRACKET
}

\author{
Essam Abdel Alim Nassar ${ }^{1}$
}

\section{ABSTRACT:}

Objective: to compare the frictional forces generated by two types of active self-ligating brackets and conventional bracket. Material and methods: Two types of active self-ligating brackets (In-Ovation $\mathbb{R}$ GAC International, Bohemia, $\mathcal{N}$ ), (SPEED, Strite Industries, Cambridge, Ontario, Canada) and one conventional bracket (Synergy, Rocky Mountain Orthodontics, Denver, Colo). Each brackett was tested with 0.016X0.016", 0.016X0.022" and 0.017X0.017" (Rocky Mountain Orthodontics, Denver, Colo) stainless steel wires. low-friction opaque ligatures (Rocky Mountain Orthodontics, Denver, Colo) were used for synergy brackets. The universal testing machine was used to measure the frictional resistance for each bracket/wire assem6ly. Results: SPEED brackets produced a significantly $(\mathcal{P}<0.001)$ more frictional resistance than both In-Ovation $R$ and Synergy brackets with all archwires' sizes. While, there was no significant difference between frictional forces of Synergy and In-Ovation R brackets ( $P>0.05)$. frictional forces increased significantly in all bracket-archwire combinations $(\mathcal{P}<0.001)$ as wire size increased from 0.016X0.016"to 0.016X0.022" and 0.017X0.017" respectively. Conclusions: SPEED $S \mathcal{L}$ brackets produced more frictional forces compared with Synergy and In-Ovation $\mathbb{R}$ brackets. The frictional resistance increased as wire size increased From 0.016X 0.016" to 0.016X0.022" and

1- Lecturer of orthodontics, Orthodontic Department, Faculty of Dentistry, Mansoura University, Mansoura, Egypt 
Egyptian

Orthodontic Journal

\subsection{X0.017". Synergy 6rackets combined with the low-friction ligatures is considered a proper choice for sliding mechanics.}

\section{INTRODUCTION}

The application of sliding mechanics during orthodontic tooth movement is often prescribed and the role of friction during this dynamic system is very critical. Friction is a force that retards or resists the relative motion of two objects in contact. ${ }^{1}$ It is the resistance to motion occurs when two objects move tangentially to each other. ${ }^{2}$ Static frictional force represents the smallest force needed to start the motion, while the force encountered during motion is the kinetic. ${ }^{3}$ In Orthodontic tooth movement, friction (static or kinetic) results from the interaction of an archwire with the sides of an orthodontic bracket or a ligature.

Different methods to reduce friction at the bracket/archwire interface has been proposed for example changing the method of ligation such as self-ligating (SL) brackets ${ }^{4,5,6,7}$ loosely tied stainless steel $^{8}$ and un- conventional ligature systems. ${ }^{9,10}$. The first SL bracket developed by Stolzenberg ${ }^{11}$ in the early 1930 s and it was concluded to shorten the treatment time and provided more comfort to the patients. ${ }^{12}$ Recently, there has been resurgence in the use of SL brackets. There are two types of SL brackets, active, that has a spring clip that presses against the archwire and passive, in which the clip just closes the slot and does not press against the wire. Both are characterised by the presence of a fourth mobile wall that converts the slot into a tube. Passive SL brackets have shown a smaller amount of friction than active SL, with the exception of the use of undersized round archwires. ${ }^{4,13}$

A controversy about friction and SL brackets still exists despite reporting a reduced friction of the SL brackets. ${ }^{14,15}$ Some authors found a significant reduction of friction with SL while others proved similar or higher friction of SL compared to conventional brackets. ${ }^{16,17}$

The aim of the present study was to compare the frictional forces of two types of active self-ligating brackets with a conventional bracket using different sizes of Stainless steel arch wires. 
Egyptian

Orthodontic Journal

\section{MATERIALS AND METHODS}

\section{Materials:}

Three types of maxillary central incisors brackets with $0.022 \times 0.025$ slot size were used in this study with total number of 30 brackets, InOvation R (GAC International ,Bohemia, NY), SPEED (Strite Industries, Cambridge, Ontario, Canada) and Synergy (Rocky Mountain Orthodontics, Denver, Colo) Figure 1. The first and the second are active SL brackets and the last is conventional bracket. Synergy low-friction opaque ligatures (Rocky Mountain Orthodontics, Denver, Colo) were used with synergy brackets. Three sizes 0.016 X0.016", 0.016 X0.022" and $0.017 x 0.017$ " of stainless steel (St.St) wires (Rocky Mountain Orthodontics, Denever, Colo) were investigated against each bracket's type.

\section{Methods:}

The force of friction was measured by universal testing machine (LLOYD, England).In order to mount the bracket /archwire couple for testing on the universal testing machine, a designed jig to hold and maintain the bracket/archwire couple in perfect alignment was used. Pieces of 6061 aluminium sheet metal were cut with a centre line scribed length wise down the middle of each wafer.

A sample bracket was placed at the marked line and the middle of the bracket was aligned along the centreline and glued by $\alpha$-cyanoacrylate adhesive (Amir Alpha, Egypt). A second wafer for each test device was prepared in a similar manner and an alignment bracket was secured in place. A piece of wire $5.0 \mathrm{~cm}$ length was glued to the alignment bracket. (Figure 2) A binder clip was used to grasp the two wafers together.

Each bracket /archwire combination was attached to the crosshead of the universal testing machine via the jig. The computer measured the force needed to pull the test wire along the test brackets and displayed the data values graphically as the wire was pulled a distance approximately $10 \mathrm{~mm}$ at a cross head speed $5 \mathrm{~mm} /$ minute.

Static friction was measured as the value of force needed to start the archwire sliding through the bracket jig assembly. The force was measured as the maximal initial rise on the "force of resistance versus sliding distance" graph. 


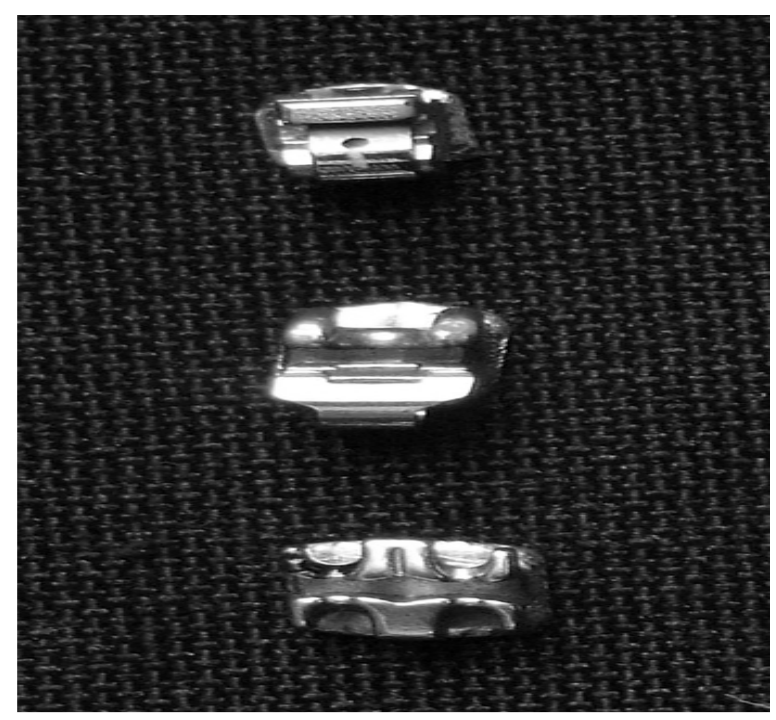

Figure1: Shows Speed, In-Ovation and Synergy brackets.

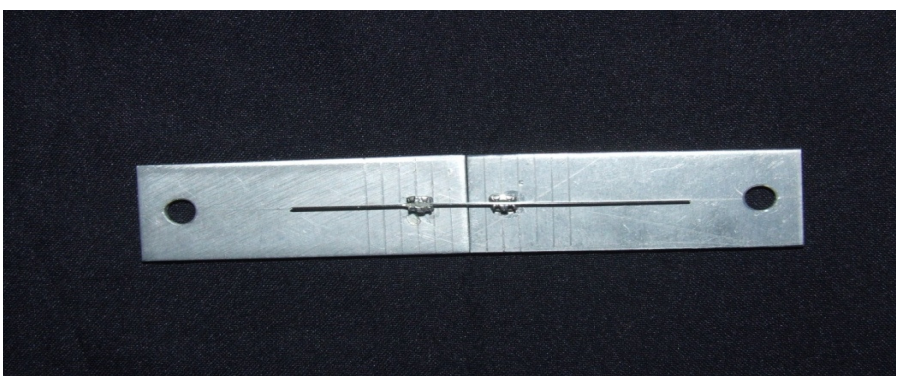

Figure 2: Showis synergy bracket and an alignment bracket assembly

\section{Statistical analysis:}

Descriptive statistics, including means and standard deviation were calculated for static frictional forces between each bracket/archwire combination using statistical software (version 14, SPSS, Chicago, IL). Analysis of variance (ANOVA) declared the significance of the effects of bracket types and archwire sizes. Post Hoc Tukey HSD Multiple comparisons tested inter-group significance. Significance for all statistical tests was predetermined at $\mathrm{P}<0.05$. 


\section{RESULTS}

Means and Standard deviations of frictional forces in grams for SPEED, In-Ovation $\mathrm{R}$ and Synergy were presented in table 1and figure 3. The lowest frictional force $(16.6 \pm 4.6)$ grams was recorded with In-Ovation $\mathrm{R}$ bracket with 0.016X0.016" St.St archwire while the highest was recorded with SPEED bracket and 0.017X0.017" St.St archwire (90.5 \pm 7.5$)$ grams. Analysis of variance results (table 2) indicated that the brackets as well as the different archwires sizes had significant effect $(\mathrm{P}<0.001)$ on the friction. Moreover, Post Hoc Tuckey HSD (table 3) revealed a significant difference of frictional forces between SPEED and both Synergy and In-Ovation R brackets with the three sizes of archwires $(\mathrm{P}<0.001)$. On the other hand, there was no significant difference between frictional forces of In-Ovation R and Synergy brackets with the three sizes of archwires $(\mathrm{P}>0.05)$.

Table 1: Means and standard deviations of frictional forces in grams for SPEED, In-Ovation R and Synergy brackets with different sizes of St.St wire.

\begin{tabular}{|l|c|c|c|}
\hline \multirow{2}{*}{ Bracket Type } & \multicolumn{3}{|c|}{ Archwire } \\
\cline { 2 - 4 } & $\mathbf{0 . 0 1 6 X 0 . 0 1 6 ”}$ & $\mathbf{0 . 0 1 6 X 0 . 0 2 2} "$ & $\mathbf{0 . 0 1 7 X 0 . 0 1 7}$ ” \\
\cline { 2 - 4 } & Mean \pm SD & Mean \pm SD & Mean \pm SD \\
\hline SPEED & $34.8 \pm 5.8$ & $67.9 \pm 5.4$ & $90.5 \pm 7.5$ \\
\hline In-Ovation R & $16.6 \pm 4.6$ & $34.8 \pm 5.8$ & $61.5 \pm 5.6$ \\
\hline Synergy & $18.3 \pm 4.2$ & $36 \pm 6.5$ & $66.3 \pm 1.3$ \\
\hline
\end{tabular}

Table 2: Shows the results of analysis of variance (ANOVA) declaring the effects of bracket types and archwire sizes as variables.

\begin{tabular}{|c|c|c|c|c|c|c|}
\hline \multirow{2}{*}{ Wire } & & $\begin{array}{c}\text { Sum of } \\
\text { squares }\end{array}$ & df & $\begin{array}{c}\text { Mean } \\
\text { square }\end{array}$ & F & Sig. \\
\hline 0.016X0.016" & Between Groups & 8131.4 & 2 & 4065.7 & 43.2 & $0.000^{*}$ \\
& Within Groups & 2538.1 & 27 & 94 & & \\
& Total & 10669 & 29 & & & \\
\hline 0.016X0.022" & Between Groups & 28195.4 & 2 & 14097 & 99 & $0.000^{*}$ \\
& Within Groups & 3838 & 27 & 142 & & \\
& Total & 32033 & 29 & & & \\
\hline $\mathbf{0 . 0 1 7 X 0 . 0 1 7 "}$ & Between Groups & 19400 & 2 & 9700 & 55.4 & $0.000 *$ \\
& Within Groups & 4725 & 27 & 175 & & \\
& Total & 24125.3 & 29 & & & \\
\hline
\end{tabular}

Significant at $\mathrm{P}<0.05$ 
Egyptian

Orthodontic Journal

Table 3: Post Hoc Tuckey HSD multiple comparisons between the tested groups.

\begin{tabular}{|c|c|c|c|c|c|}
\hline $\begin{array}{c}\text { Dependant Variable } \\
\text { Wire }\end{array}$ & $\begin{array}{l}\text { (I) } \\
\mathrm{Br}\end{array}$ & $\begin{array}{l}\text { (J) } \\
\text { t }\end{array}$ & $\begin{array}{c}\text { Mean } \\
\text { Difference }\end{array}$ & Std Error & Sig \\
\hline \multirow[t]{3}{*}{$0.016 \times 0.016 "$} & 1 & 2 & 18.3 & 4.33 & $.000 *$ \\
\hline & & 3 & 16.5 & 4.33 & $.000^{*}$ \\
\hline & 2 & 3 & -1.7 & 4.33 & .716 \\
\hline \multirow[t]{3}{*}{$0.016 \times 0.022 "$} & 1 & 2 & 31.9 & 5.33 & $.000^{*}$ \\
\hline & & 3 & 33.1 & 5.33 & $.000^{*}$ \\
\hline & 2 & 3 & -1.2 & 5.33 & .895 \\
\hline \multirow[t]{3}{*}{$0.017 \times 0.017 "$} & 1 & 2 & 29 & 5.91 & $.000^{*}$ \\
\hline & & 3 & 24.2 & 5.91 & $.000^{*}$ \\
\hline & 2 & 3 & 4.8 & 5.91 & .254 \\
\hline
\end{tabular}

Where 1: SPEED, 2: In-Ovation R and 3: Synergy.

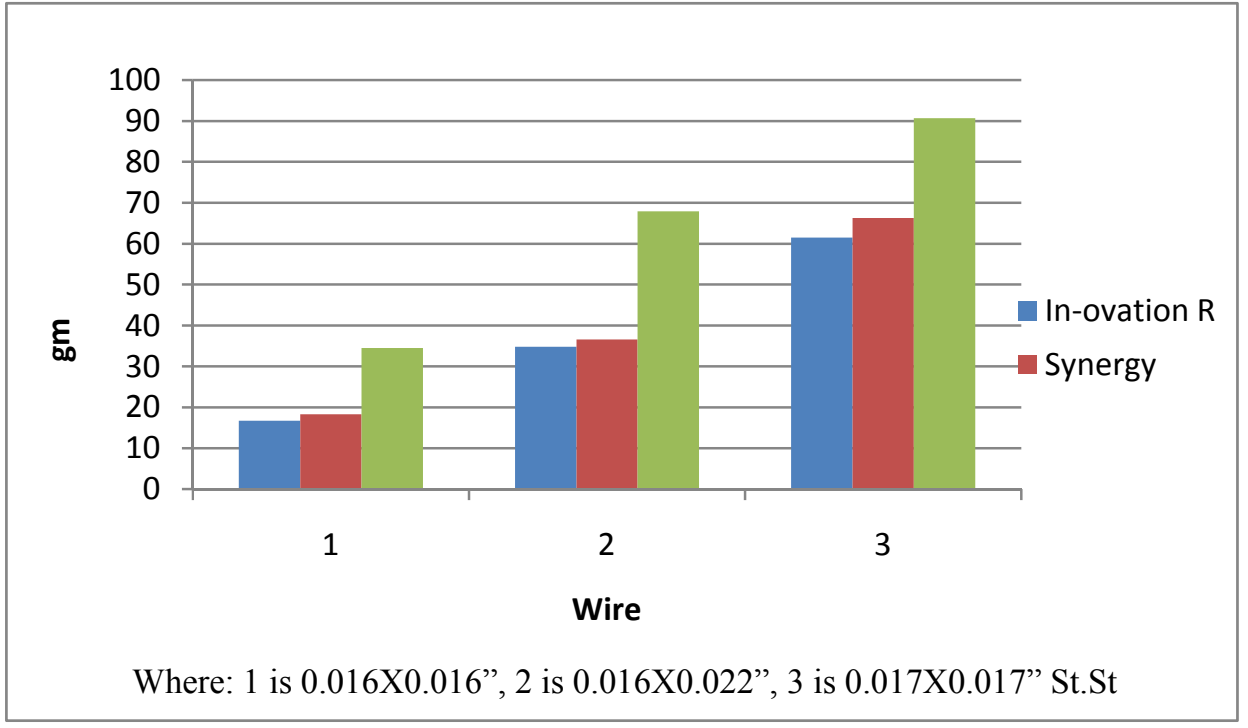

Figure 3: The means of frictional forces in grams for 0.016X0.016", 0.016X0.022"and 0.017 X0.017" St.St with In-Ovation R, Synergy and SPEED brackets. 
Egyptian

Orthodontic Journal

\section{DISCUSSION}

Approximately $50 \%$ of the force necessary to start tooth movement is needed to overcome the frictional forces generated between fixed appliances' components such as archwires, brackets and ligatures. ${ }^{18}$ Therefore, a decrease in frictional resistance tends to be beneficial for both hard and soft tissue responses as well as better patient comfort.$^{19,20}$

This study focused upon the static friction as it is considered to be of greater value in orthodontic mechanotherapy. Tooth movement along archwire is a serious of intermittent movements and not contentious. Static friction needs to be overcome with movement of each tooth. ${ }^{21}$

Regarding the bracket type, The SPEED SL brackets demonstrated a significantly $(\mathrm{P}<0.001)$ more frictional resistance than both In-Ovation $\mathrm{R}$ and Synergy brackets with all archwires' sizes. These results were in agreement with other studies that proved a greater frictional resistance with SPEED brackets compared to In-Ovation brackets. ${ }^{22.23}$ The lowest frictional resistances were recorded with In-Ovation SL brackets. However, There was no statistical difference between the frictional values for In-Ovation and Synergy brackets $(\mathrm{P}>0.05)$. Synergy has special design with rounded slot wall and six tie wings. Data of this study revealed that, the combination of Synergy bracket and Synergy low-friction ligatures resulted in a significantly less friction in comparison with SPEED SL bracket .It has been found that such combination is capable of achieving a force level to produce tooth movement during aligning and levelling of apically displaced tooth using 0.012 and 0.14 super elastic nickel titanium arch wire. ${ }^{24}$ Additionally, based on the results of this study, Synergy brackets plus Synergy ligatures represent a satisfactory system during sliding and space closure stages when larger wires' dimensions are used. Synergy system combination could substitute SL brackets eliminating its disadvantages such as higher coast, possible breakage of the clip or slide and higher profile due to their sophisticated design.

Considering the wire size, results of this study showed a significant increase in frictional resistance as wire size increases from $0.016 \times 0.016$ " to $0.016 \mathrm{X} 0.022$ " and $0.017 \mathrm{X} 0.017$ ". These results are in agreement with 
previous studies that reported increased frictional forces as wire size increased as well as the geometry of the archwire enlarges from round to square to rectangular. ${ }^{25,26,27,28}$ Unfortunately, $0.017 \mathrm{X} 0.017$ " square wire produced greater friction when compared to the rectangular $0.016 \mathrm{X} 0.022$ " in the present study. However, a possible explanation to such finding is that the frictional resistance is determined basically by the difference in the vertical dimension of archwire. ${ }^{29}$

\section{CONCLUSION}

SPEED SL brackets produced more frictional forces compared with Synergy and In-Ovation $\mathrm{R}$ brackets. The frictional resistance increased as wire size increases from $0.016 \mathrm{X} 0.016 "$ to $0.016 \mathrm{X} 0.022 "$ and $0.017 \mathrm{X} 0.017$ '. Finally, Synergy brackets combined with low-friction ligatures could represent a proper substitute to active SL brackets.

\section{REFERENCES}

1. Loftus BP, Årtun J, Nicholls JI, Alonzo TA, Stoner JA. Evaluation of friction during sliding tooth movement in various bracket-arch wire combinations. Am J Orthod Dentofacial Orthop 1999;116:336-345.

2. Tecco S, Festa F, Caputi S, Traini T, Di Lorio D, D'Attillio M. Friction of conventional and self- ligating brackets using a 10 bracket model. Angle Orthod 2005;75:1041-5.

3. Omana HM, Moore RN, Bagby MD. Frictional properties of metal and ceramic brackets. J Clin Orthod 1992;27:425-432.

4. Thomas S, Sheriff M, Birnie D. A comparative in vitro study of the frictional characteristics of two types of self-ligating brackets and two types of pre-adjusted edgewise brackets tied with elastomeric ligature. Eur J Orthod 1998;20:589-569.

5. Thostenson GA, Kusy RP. Comparison of resistance to sliding between different self-ligating brackets with second-order angulation in the dry and wet saliva state. Am J Orthod Dentofacial Orthop 2002;121:472-482. 
6. Henao SP, Kusy RP. Frictional evaluations of dental typodont models using four self-ligating designs and a conventional design. Angle Orthod 2005;75:75-85.

7. Miles PG. Self-ligating brackets vs conventional twin brackets during en-masse space closure with sliding mechanics. Am J Orthod Dentofacial Orthop 2007;132:223-5.

8. Hain M, Dhopatkar A, Rock P. The effect of ligation method on friction in sliding mechanics. Am J Orthod Dentofacial Orthop 2003; 123:416-22.

9. Baccetti T, Franchi L. Friction produced by types of elastomeric ligatures in treatment mechanics with the preadjusted appliances. Angle Orthod 2006; 76:211-6.

10. Franchi L, Baccetti T. Forces released during alignment with a preadjusted appliances with different types of elastomeric ligatures. Am J Orthod Dentofacial Orthop 2006; 129:687-90.

11. Stolzenberg J. The Russel attachment and its improved advantages. Int J Orthod Dent Child 1935;21:837-840.

12. Stolzenberg J. The Efficiency of the Russel attachment. Am J Orthod Oral Surg 1946;32:572-82..

13. Pizzoni L, Ravnholt G, Melsen B. Frictional forces related to self-ligating brackets. Eur J Orthod 1998;20:283-291.

14. Harradine NW. Self ligating brackets and treatment efficiency . Clin Orthod Res 2001;4:220-227.

15. Turnbull NR, Birnie DJ. Treatment efficiency of conventional vs self-ligating brackets: effects of archwire size and material. Am J Orthod Dentofacial Orthop 2007; 131:395-399.

16. Bednar JR, Gruendeman GW, Sandrik JL. A comparative study of frictional forces between orthodontic brackets and arch wires. Am J Orthod Dentofacial Orthop 1991; 100:513-522. 
17. Redlich M, Mayer Y, Harari D, Lewinststein I. In Vitro study of frictional forces during sliding mechanics of "reduced -friction" brackets. Am J Orthod Dentofacial Orthop 2003; 124:69-73.

18. Proffit WR, Fields HW Jr, Sarver DM. Contemporary orthodontics $.4^{\text {th }}$ ed. St Louis: Mosby/Elsevier;2007.

19. Shivapuja PK, Berger J. A comparative study of conventional ligation and self-ligation bracket systems. Am J Orthod Dentofacial Orthop 1994; 106:472-480.

20. Wadhwa PK, Kwon HK, Sciote JJ. Friction resistance in ceramic and metal brackets. J Clin Orthod 2004; 38:35-8.

21. Fourie Z, Özcan M, Sandham A. Effect of dental arch convexity and type of archwire on frictional forces. Am J Orthod Dentofacial Orthop 2009; 136:14.e1-14.e7.

22. Thorstenson GA, Kusy RP. Comparison of resistance to sliding between different self-ligating brackets with second-order angulation in the dry state. Am J Orthod Dentofacial Orthop 2002;121 :472-82.

23. Budd S, Daskalogiannakis J, Tompson BD. A Study of the frictional characteristics of four commercially available self-ligating bracket systems. Eur J Orthod 2008;30:645-653.

24. Baccetti T, Frachi L, Camporesi M,Defraia E, Barbato E. Forces produced by different nonconventional bracket or ligature systems during alignment of apically displaced teeth. Angle Orthod 2009;79:533-539.

25. Kapila S, Angolkar PV, Duncanson MG Jr, Nanda RS. Evaluation of friction between edgewise stainless steel brackets and orthodontic wires of four alloys. Am J Orthod Dentofacial Orthop 1990; 98:117-126.

26. Drescher D, Bourauel C, Schumacher HA. Frictional forces between bracket and arch wire. Am J Orthod Dentofacial Orthop 1989; 96:397-404.

27. Sims AP, Waters NE, Birnie DJ, Pethybridge RJ. A Comparison of the forces required to produce tooth movement in vitro using two self- ligating brackets and a pre-adjusted bracket employing two types of ligation. Eur J Orthod 1993;15:377-385. 
28. Tecco S, Di Lorio D, Cordasco G, Verrocchi I, Festa F. An in vitro investigation of the influence of self-ligating brackets, low friction ligatures, and archwire on frictional resistance. Eur J Orthod 2007;29:390-397.

29. Smith DV, Rossouw PE, Watson P. Quantified simulation of canine retraction: Evaluation of frictional resistance. Semin Orthod 2003;9:262-280. 